\title{
Detection of selected pathogens in Apennine wolf (Canis lupus italicus) by a non-invasive GPS-based telemetry sampling of two packs from Majella National Park, Italy
}

\author{
Cristina E. Di Francesco ${ }^{1}$ (D) Camilla Smoglica ${ }^{1} \cdot$ Barbara Paoletti $^{1} \cdot$ Simone Angelucci $^{2} \cdot$ Marco Innocenti $^{2}$. \\ Antonio Antonucci ${ }^{2} \cdot$ Giovanna Di Domenico $^{2} \cdot$ Fulvio Marsilio $^{1}$
}

Received: 29 May 2019 / Revised: 18 September 2019 / Accepted: 21 September 2019 / Published online: 25 October 2019

(C) Springer-Verlag GmbH Germany, part of Springer Nature 2019

\begin{abstract}
In this study, a multi-pathogens survey was conducted to verify the sanitary status of two Italian wolf packs of Majella National Park. Twenty fecal samples (10/pack) were collected using a sampling protocol, based on the combining data from radio-collared wolves with geographic information system (GIS) analysis, allowing to mark off the home range of packs and to recover groupspecific and high-quality specimens. Virological screening against the most prevalent canine viruses (protoparvovirus, distemper virus, adenoviruses, and coronaviruses) was carried out by molecular methods, while parasites were detected by means of copromicroscopic and molecular analysis. Canine parvovirus type $2 \mathrm{~b}(\mathrm{CPV}-2 \mathrm{~b})$ is the most prevalent virus in both packs (7/20), followed by canine adenovirus type 2 (CAdV-2), while no sequences of canine distemper virus and coronaviruses were detected. The sequence analysis of the viruses demonstrated the domestic origin of the infection, highlighting the importance of vaccination of local dogs in order to reduce the risk of exposure of wildlife to these pathogens. Fourteen samples resulted positive for parasites. Capillaria aerophila (sin. Eucoleus aerophilus), Ancylostoma/Uncinaria, Trichuris vulpis eggs, Sarcocystis spp., Cystoisospora canis, and Angiostrongylus vasorum larvae were identified. Echinococcus granulosus sensu stricto (ovine genotype G1) and Giardia duodenalis (canid-specific Assemblage C) were also characterized, providing insights into the wolves' diet and their effects on environmental contamination. The sampling protocol applied in this study, based on a multidisciplinary approach, represents an innovative tool for the survey of Apennine wolf, able to integrate sanitary data with the ecological and demographic features of this population.
\end{abstract}

Keywords Canis lupus italicus $\cdot$ Global positioning system $\cdot$ Fecal samples $\cdot$ Viruses $\cdot$ Parasites

\section{Introduction}

The Majella National Park (MNP) is a protected area of high ecological value for the safeguard of the Apennine wolf (Canis lupus italicus) population, and it covers a vast moun-

Electronic supplementary material The online version of this article (https://doi.org/10.1007/s10344-019-1326-y) contains supplementary material, which is available to authorized users.

Cristina E. Di Francesco

cedifrancesco@unite.it

1 Faculty of Veterinary Medicine, University of Teramo, Loc. Piano D’Accio, 64100 Teramo, Italy

2 Majella National Park, Via Badia 28, 67039 Sulmona, Italy tainous area of about $740 \mathrm{~km}^{2}$ in the Abruzzi region along the Apennines of South-Central Italy.

Based on the last studies, the MNP wolf population is estimated at 90 to 100 animals distributed in $10-11$ packs, showing a high population density (Valerio et al. 2009; Galaverni et al. 2016).

Recently, the MNP developed a coordinated plan of sustainable measures for the conservation of the wolf population in the Apennines, including specific strategies for the reduction of sanitary risks resulting from the sympatric canine populations and the interactions between wolves and dogs (LIFE08/NAT/IT/00325 n.d.).

Pathogens that could be a threat to the health status of wolf population are canine parvovirus type 2 (CPV-2), now classified as carnivore protoparvovirus 1 , canine distemper virus $(\mathrm{CDV})$, canine coronaviruses (CCoVs), and canine 
adenoviruses (CadVs), along with endoparasites characterized by a partial or complete life cycle in the intestinal tract (Borecka et al. 2013; Millán et al. 2016). In Italy, the most recent studies documented the occurrence of aforementioned viruses in the Apennine wolf population, with particular regard to the variant $b$ of CPV-2, canine adenovirus CadV-1, and CadV-2, a pantropic strain of CCoVs and almost two different lineages of CDV (Di Sabatino et al. 2014; Pizzurro et al. 2017; Alfano et al. 2018). Furthermore, a survey to investigate the distribution of intestinal helminths in wolves of MNP revealed high values of polyspecific infections of roundworms, such as capillariids, Ancylostoma/Uncinaria, and Trichuris vulpis(Paoletti et al. 2017).

The majority of these studies were conducted by noninvasive monitoring procedures analyzing the fecal samples opportunistically collected along the trails, off-road, and transects detected by means of wolf howling and snow tracking sessions, and/or recovering the carcasses (Millán et al. 2016; Pizzurro et al. 2017; Alfano et al. 2018).

In order to discriminate the wolf feces from those of other free-ranging species, multiple criteria (diameter and volume of the scats) are required, but the reliability of them appears to be lacking. Moreover, the feces collected along the roads and trails were largely from dominant pack members (Blanco and Cortés 2012) and the carcasses of wolves could be recovered in a compromised preservation conditions with advanced autolysis.

In this context, a correct sanitary monitoring should be carried out by means of standardized procedures of sampling, in order to obtain high-quality samples, suitable for laboratory investigations purposes and representative of the groups of animals.

In this study, a sampling protocol, based on the combining data downloaded from GPS-collared adult wolves with geographic information system (GIS) analysis, was applied in order to collect wolf-specific and relatively fresh stool specimens for virological and parasitological investigations, and to relate the diagnostic results with spatial distribution, health status, and ecological data obtained from two monitored packs.

\section{Material and methods}

\section{Investigated packs and sampling}

During the summer 2017, two female adults were captured in different sites with evidence of resident and breeding wolf packs. Capture procedures (Fremont foot snares and chemical immobilization) and animal handling were carried out according to the European and National legislations (Council Directive 92/43/EEC; DPR 357/97) and approved by the Italian Ministry of for Environment, Land and Sea
Protection. Once immobilized, each animal was fitted with a GPS-GSM collar (Followit, Sweden). The wolves appeared in good condition without any clinical signs of disease.

The collars were programmed to take 48 localizations $/ 24 \mathrm{~h}$ for 10 days/month (high rate configuration) during the sampling sessions, and 8 localizations $/ 24 \mathrm{~h}$ (low rate configuration) for the rest of the monitoring period (from July to December 2017). The adaptive kernel (95\% contour, 50\% core area) of each pack was estimated using least squares cross-validation method (hLSCV)(Worton 1989; Seamen and Powell 1996). According to the protocol already in use for wolf food ecology and resting sites study in the MNP territories, a cluster was considered so when at least two consecutive localizations, within a radius of $100 \mathrm{~m}$, linked with the activity on the $x / y$ axes, were recorded (Sand et al. 2005).

The GPS positions registered by radio collars along with the video data obtained from camera traps, previously positioned in the study area, allowed to prove that the monitored wolves belonged to two different packs, named Majella Centrale (MC) and Bassa Valle dell'Orta (BVO). The MC pack resulted a recent formation unit, organized in few animals (down to 4 wolves), whose home range $\left(28 \mathrm{~km}^{2}\right)$ is entirely included in the protected area. Instead, the BVO pack appeared to be a stable and reproductive nuclear family (at least 7 wolves) and the relative home range $\left(40 \mathrm{~km}^{2}\right)$, partially outside the MNP boundaries, comprised villages, and other human infrastructures. No evidence of serious effects of disease or significant changes in wolves' behavior was observed in the packs. During the study, a total of 9 kill sites (4/BVO and 5/MC pack) with evidence of wolf predation on wild ungulates (6 carcasses) and domestic small ruminants (3 carcasses) were identified for both packs.

From September to October 2017, 38 suitable clusters, based on space-time distribution, landscape features, and safe accessibility, were selected analyzing the locations data obtained daily from the collars by the Followit GEO $^{\text {TM }}$ web portal (Followit, Sweden) and the geographic information system (www.qgis.org). For each cluster, a circular area with a radius of $100 \mathrm{~m}$, starting from the geometric center, was identified and visited within 12 $24 \mathrm{~h}$ following parallel circular transects covering the entire space. All fresh scats detected in the circular area, and according to morphological characters for the species (diameter, volume and presence of hairs), are recovered for a total of 20 fresh fecal samples (10/pack) (Fig. 1).

\section{Virological and parasitological investigations}

All samples were split into two aliquots for virological and parasitological investigations, and early frozen $\left(-20^{\circ} \mathrm{C}\right)$ until analyzed.

Conventional PCR and RT-PCR protocols were carried out against canine parvovirus type 2 (CPV-2), canine 

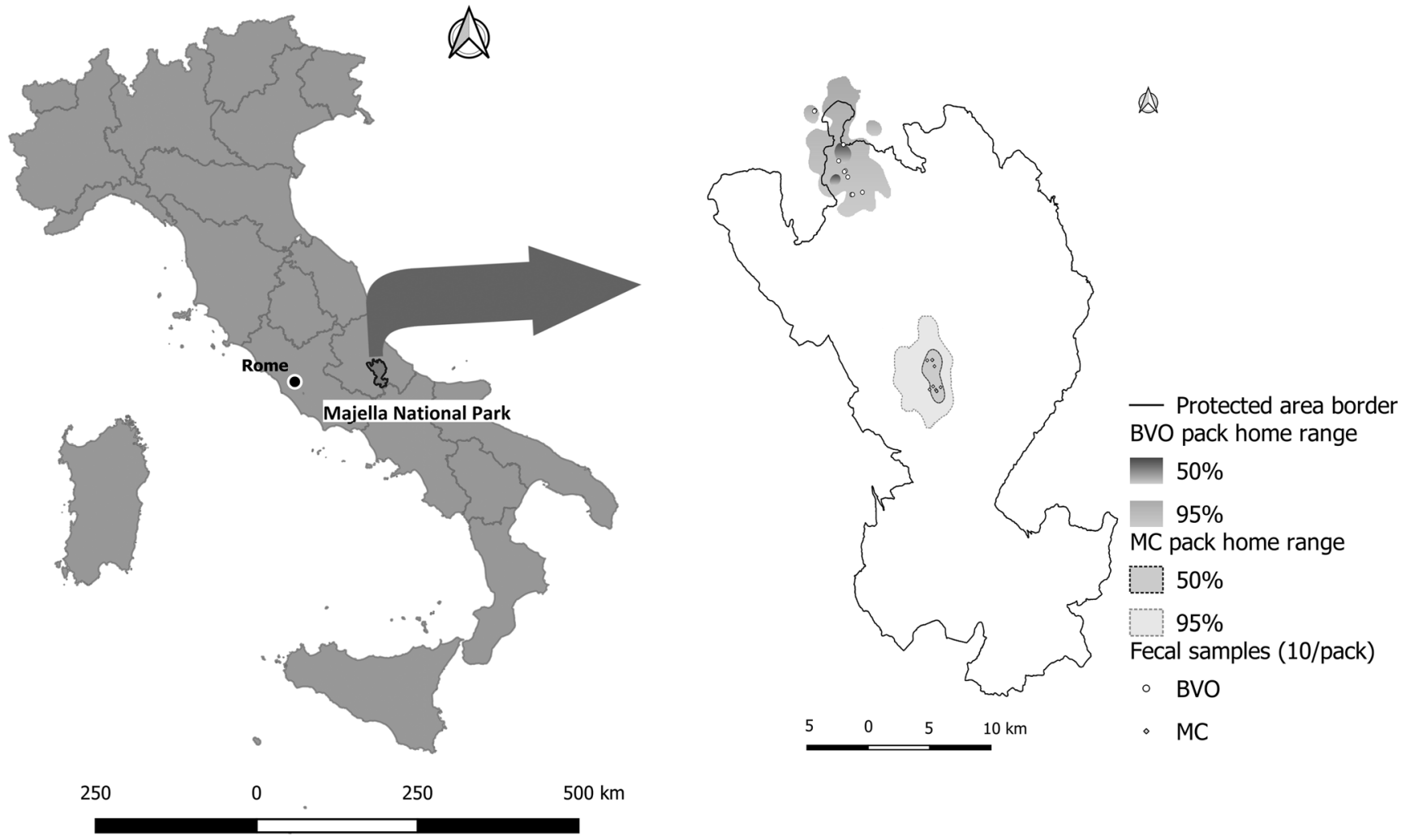

Fig. 1 Map of Italy with the Majella National Park (MNP) boundaries and geographic distribution collected samples in both MC and BVO packs home range

adenoviruses type 1 and 2 (CAdV-1 and CAdV-2), canine distemper virus (CDV), and canine coronaviruses (CCoVs) (Online Resource S1). For this purpose, total DNA and RNA were extracted from the feces using the Brief Protocol Exgene TM Stool DNA mini kit (GeneAll®, South Korea) and the RNeasy® Mini Kit (Qiagen, Italy).

The amplicons obtained were purified and sequenced in order to verify the positive results of PCR probes. The complete sequence VP2 gene of CPV-2 was obtained from one positive sample and submitted to the GenBank database under the accession number MH614271.

Nucleotide sequences were assembled and analyzed using the CHROMAS software, FASTA (http://www.ebi.ac.uk/ fasta33), Basic Local Alignment Search Tool (BLAST), and Clustal Omega (http://www.ebi.ac.uk/Tools/msa/clustalo). A maximum likelihood (ML) phylogenetic tree of the fulllength sequences of VP2 region deposited in GenBank was constructed using MEGA v7.0.26 (Kumar et al. 2016).

For parasitological exams, fecal samples were examined by means of copromicroscopic and molecular analysis, respectively. Copromicroscopic examination was performed with a classical flotation procedure, using a saturated $\mathrm{NaNO}_{3}$ solution (specific gravity 1.340) (Euzeby 1981). Parasite elements were identified according to their morphological features and micrometric measurements at $\times 40$ and $\times 100$ magnifications (Sprent 1968; Sloss et al. 1994).
In addition, genomic DNA was extracted from an aliquot of each sample using the commercial ZR Fecal DNA Mini Prep Kit (Zymo Research, USA). The DNA extracts were subjected to different PCR protocols. A fragment of the Giardia spp. gene encoding for the small subunitrRNA(SSU-rRNA) and a fragment internal to the COWP gene of Cryptosporidium, were amplified according to the protocols previously described (Traversa et al. 2004). Additionally, the occurrence of Echinococcus spp. was evaluated using primers pair JB3/JB4.5 able to amplify a fragment of a mitochondrial gene, cytochrome $\mathrm{c}$ oxidase subunit I (COI), as described previously by Bowles and McManus (1993). Moreover, appropriate negative and positive controls were included in each PCR run.

The amplicons obtained were purified and sequenced. Finally, nucleotide sequences were assembled and compared with those available in the GenBank database using the Clustal and BLAST programs.

\section{Results}

\section{Virological and parasitological investigations}

Out of 20 fecal specimens, 2 samples from BVO pack and 5 from $\mathrm{MC}$ pack were positive for parvovirus DNA sequences. 
Positive samples were confirmed as variant $2 \mathrm{~b}$ of the field strain CPV-2 highlighting an identity of $100 \%$ among the viral sequences obtained from both BVO and MC packs. The phylogenetic analysis of the full-length VP2 gene showed that the wolf CPV-2b strain under study clustered with analogous viral strains obtained from Italian domestic dog, but appeared distinct from the wildlife parvoviruses coming from USA, Canada, and Portugal (Fig. 2).

Two samples from BVO pack and one from MC pack were found positive for CAdV-2 DNA. Noteworthy, one additional BVO pack's specimen contained Porcine adenovirus type 3 (PAV-3) DNA fragment.

A fragment of CAdV-2 E3 gene was compared with analogous sequences and the analysis revealed the closest identity (100\%) with the strain Toronto A26/61. A similar identity, but with a minor coverage (87-88\%), was found with the dog strain 60-2011 (Genbank KF676978.1) and the red fox (Vulpes vulpes) strain 113-3F-c04 (Genbank JX416842.1), both detected in Italy. A partial coverage (28-30\%), with an identity of $100 \%$ and $96 \%$, was also obtained in comparison with two Italian wolf strains (Genbank MF356370.1 and MF356371.1) detected in Northern Italy.

Regards PAV-3, the partial cds of pol gene showed a $99 \%$ of identity (coverage 98\%) with the strain 6618 detected in porcine (GenBank AB026117 and AF083132) in 1998 and 1999.

Finally, no sequences of CDV and CCoVs were detected in any fecal samples (Table 1$)$.

Fourteen samples (6/BVO pack and 8/MC pack) resulted positive for parasites. Capillaria aerophila (sin. Eucoleus aerophilus), Ancylostoma/Uncinaria, Trichuris vulpis eggs, Sarcocystis spp., and Cystoisospora canis, Angiostrongylus vasorum larvae were identified. Overall, monospecific infections were found in 7 samples with $C$. aerophila being the most frequent. Moreover, polyspecific infections were found in additional 7 samples. The most frequent association was represented by Ancylostoma/Uncinaria and Capillaria aerophila(Table 1).

The molecular analysis demonstrated Giardia duodenalis and E. granulosus in sensu stricto in samples $1 / \mathrm{MC}$ pack and 2/MC pack, respectively. The sequence of Giardia showed the closest sequence homology (99\%) with G. duodenalis Assemblage C (GenBank accession number MF153912.1), while E. granulosus showed the closest sequence homology ( $100 \%$ ) with the genotype ovine G1 (Genbank accession number U50464). Finally, the DNA of Cryptosporidium spp. was not detected in any fecal samples.

\section{Discussion}

The multi-pathogen survey reported in this study was conducted on samples specifically collected from kill or resting sites of two different wolf packs by a non-invasive GPS location-based technique. Indeed, there are some advantages in this sampling method. Most previous studies investigated exposure to pathogens through serological surveys or opportunistic fecal samples and autopsy of recovered deceased animals (Almberg et al. 2009; Millán et al. 2016; Miranda et al. 2017; Pizzurro et al. 2017). Whereas, during our study, the sampling sessions were carried out visiting the suitable clusters within 12-24 $\mathrm{h}$ from their identification by means of the GPS-GSM radio collars' location tracking. In addition, the video-trapping data confirmed that the monitored wolves belonged to two different packs and moved with the other members. Therefore, this procedure allowed to recover relatively fresh samples coming from more individuals and to relate each specimen to the pack under study.

The close physical contact between group members is characteristic of social canids such as wolves, and it enhances the likelihood of within-pack transmission of pathogens (Johnson et al. 1994). Therefore, the detection of pathogens in one or more samples suggests that several members of the pack were probably exposed to the infection, as previously proposed (Molnar et al. 2014).

Apparent prevalence of CPV-2b in wolf fecal samples ranged from 20 to $50 \%$ in $\mathrm{BVO}$ and $\mathrm{MC}$ packs, respectively. These results, along with the serological monitoring carried out in the past within the MNP territories (unpublished data), suggest that the virus can be considered endemic in the wolves population of the Park, as previously observed for other wolf populations in Spain, Canada, and North America (Mech et al. 2008; Almberg et al. 2009; Nelson et al. 2012; Millán et al. 2016). It is noteworthy that in our study the sensitivity of sampling appears to be higher in comparison with other surveys (Millán et al. 2016; Miranda et al. 2017). Probably, the GPS telemetry and video-trapping data used for location tracking of the packs, along with the season of the sampling, may have improved the detection of positive samples.

The sequence analysis allowed identifying the variant $2 \mathrm{~b}$ of CPV-2 in both packs. CPV-2b was detected for the first time in Apennine wolves by Battilani et al. (2001), who revealed a very high relationship of the virus with analogous sequences derived from domestic canine population living in the same territory. Actually, CPV-2a followed by variant $2 \mathrm{~b}$ appear to be the most predominant variants in Italian dog population, while CPV-2c is the least frequently reported. In addition, the sequences of VP2 gene were grouped into four major haplotypes (H1-H4), including viral strains collected in different regions. Haplotype 1 (H1) gathered sequences of CPV-2b from Abruzzo, Veneto, Emilia Romagna, Latium, Tuscany, and Sardinia regions (Tucciarone et al. 2018). In accordance with this scenario, the phylogenetic analysis based on complete sequence of VP2 gene revealed that the CPV-2 under study clustered in the $\mathrm{H} 1$ group, while it appears to be different from analogous CPV-2b sequences derived from wildlife. 


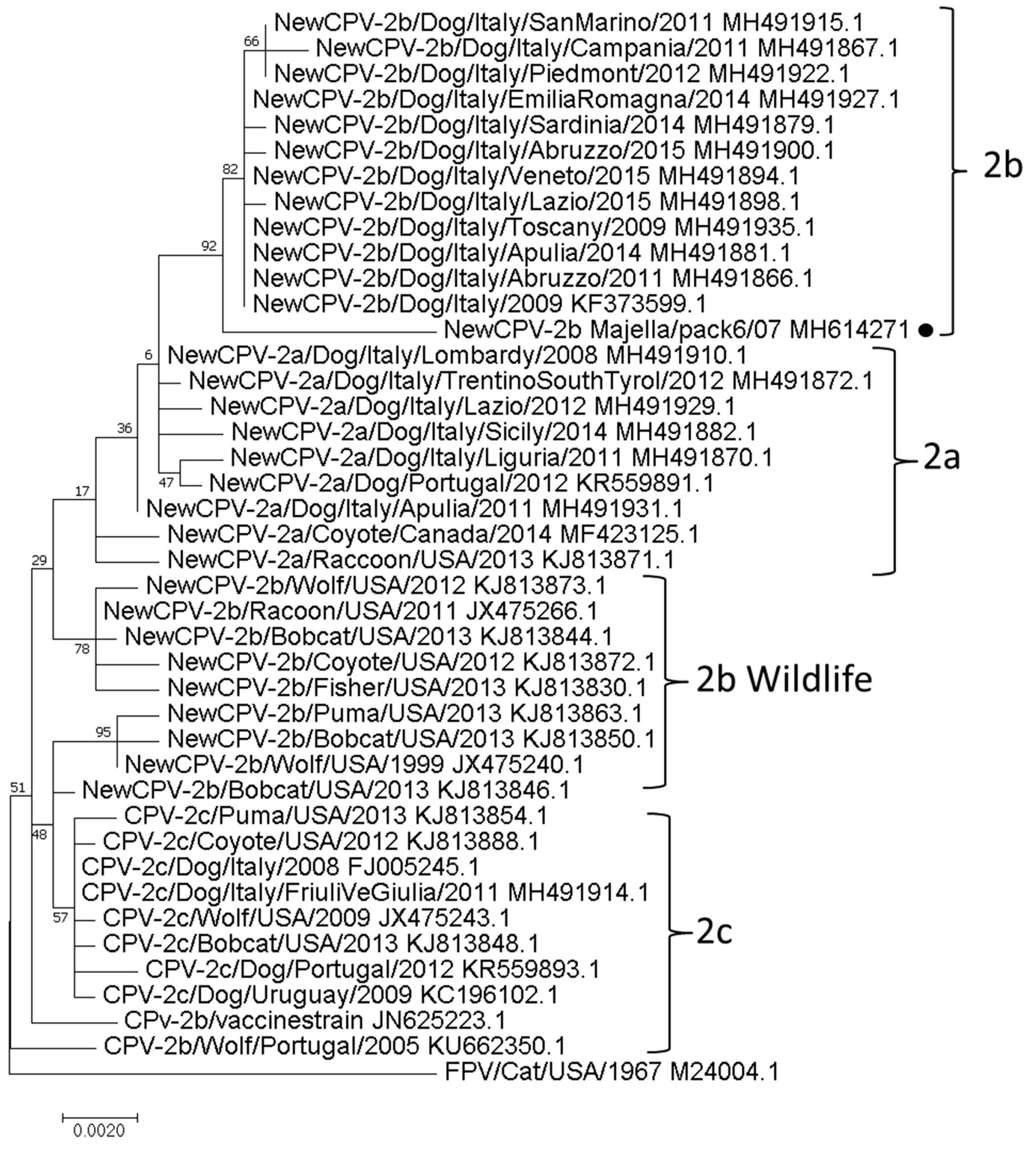

Fig. 2 Phylogenetic analysis of the VP2 complete nucleotide sequence of canine parvovirus obtained in this study. The gene was compared with 40 analogous sequences belonging to domestic and wild species. For each

Probably, the viral strain circulating in the packs is not completely adapted to the wild host and the domestic dog could represent the virus reservoir for MNP wolves. The recent increase of wolf population observed in several countries, including Italian strain, the genetic variant, species host, country of origin, year, and GenBank accession number are reported. The CPV-2 variants, $(2 \mathrm{a}, 2 \mathrm{~b}$, $2 \mathrm{c}$ ) along with the wildlife variant $2 \mathrm{~b}$ are highlighted by curly brackets

regions (Boitani et al. 2018), encouraged the maintenance of frequent contacts between wolves and sympatric dogs, mainly represented by feral and shepherd dogs. In this scenario, the local canine population can be considered a potential risk of 
Table 1 Results of virological and parasitological investigations carried out on the fecal samples collected from the packs under study

\begin{tabular}{|c|c|c|c|c|c|}
\hline Sample/Pack & CPV-2 & CAdVs & $\mathrm{CCoV}$ & CDV & Parasites \\
\hline $1 / \mathrm{BVO}$ & Neg & Neg & Neg & Neg & Ancylostoma/Uncinaria \\
\hline 2/BVO & Neg & Neg & Neg & Neg & Trichuris vulpis \\
\hline 3/BVO & Neg & Neg & Neg & Neg & Neg \\
\hline 4/BVO & Neg & Neg & Neg & Neg & Neg \\
\hline $5 / \mathrm{BVO}$ & Neg & Neg & Neg & Neg & Eucoleus spp., Ancylostoma/Uncinaria, Cystoisospora canis \\
\hline 6/BVO & Neg & CAdV-2 & Neg & Neg & Neg \\
\hline 7/BVO & CPV-2b & PAdV-3 & Neg & $\mathrm{Neg}$ & Capillaria aerophila \\
\hline 8/BVO & Neg & CAdV-2 & Neg & Neg & Capillaria aerophila, Angiostrongylus vasorum, Trichuris vulpis, Ancylostoma/Uncinaria \\
\hline 9/BVO & Neg & $\mathrm{Neg}$ & Neg & Neg & Neg \\
\hline 10/BVO & CPV-2b & Neg & Neg & Neg & Capillaria aerophila, Ancylostoma/Uncinaria \\
\hline 11/MC & CPV-2b & Neg & Neg & Neg & Capillaria aerophila, Cystoisospora canis, Ancylostoma/Uncinaria \\
\hline $12 / \mathrm{MC}$ & Neg & Neg & Neg & Neg & Capillaria aerophila \\
\hline $13 / \mathrm{MC}$ & CPV-2b & Neg & Neg & Neg & Capillaria aerophila \\
\hline $14 / \mathrm{MC}$ & CPV-2b & Neg & Neg & Neg & Capillaria aerophila, Sarcocystis spp., Ancylostoma/Uncinaria \\
\hline 15/MC & Neg & Neg & Neg & Neg & Capillaria aerophila \\
\hline 16/MC & Neg & CAdV-2 & $\mathrm{Neg}$ & Neg & Neg \\
\hline 17/MC & Neg & Neg & Neg & Neg & Neg \\
\hline 18/MC & Neg & Neg & Neg & Neg & Cystoisospora canis \\
\hline 19/MC & CPV-2b & Neg & Neg & $\mathrm{Neg}$ & Capillaria aerophila, Sarcocystis spp., Ancylostoma/Uncinaria \\
\hline 20/MC & CPV-2b & Neg & Neg & $\mathrm{Neg}$ & Capillaria aerophila, Ancylostoma/Uncinaria \\
\hline
\end{tabular}

Neg: negative; BVO: Bassa Valle dell'Orta pack; MC: Majella Centrale pack

frequent exposure to the virus for wolf packs, and the implementation of the vaccination of sympatric dogs along with the control of stray or abandoned animals should be encouraged.

Partial sequences of CadV-2 were detected in fecal samples derived from both $\mathrm{MC}$ and BVO packs.

This is the first report of the virus in Central Apennine wolves, consistent with similar findings recently documented in Northern and Southern Italy (Melegari et al. 2018; Alfano et al. 2018). In Italy, in the past, canine adenoviruses were described only in foxes (Balboni et al. 2013), except for CadV-1 reported in a wolf found dead and showing hepatic lesions referred to the infection. These data suggest that CadV2 can be considered emerging in free-ranging wolves and additional surveys should be carried out to monitoring changes in the epidemiology of the infection.

Interestingly, one sample resulted positive for PAdV-3. Porcine adenoviruses are commonly isolated from the gastrointestinal tract and fecal samples of swine, and generally cause subclinical infections (Horak and Leedom Larson 2016). In addition, they can be found in residual waters and sludge collected from livestock farms, making PAdVs specific markers of fecal contamination of the environment (De Motes et al. 2004; Hundesa et al. 2010; Garcia et al. 2012). In our study, both the MC and BVO packs showed a predatory activity on the wild boar, and even if no data about the distribution of PAdVs in wildlife are available, it is not ruled out that the presence of virus could be linked to the diet of the packs. On the other hand, the positivity emerged only in the BVO pack, whose home range includes pig farms, slaughterhouse, and meat-processing plant, as proved from radio telemetry data. Based on these data, the PAdV-3 positive sample can be more related to the environmental contamination, rather than to the predatory activity on local wild boar population. In this respect, the BVO pack appear to inhabit a territory markedly influenced by human activities that require a rapid response by the animals to environmental changes, as already described for the ecological trap in other wild species (Hale and Swearer 2016).

As regards $\mathrm{CDV}$ and $\mathrm{CCoVs}$, the negative results obtained by RT-PCR screening suggest that both viruses are not harbored in the wolf population under study, even if other variables as season of sampling, low number of specimens, and the higher sensitivity to degradation of RNA viruses than DNA ones could not be ruled out (Bergner et al. 2019).

The results of parasitological investigations confirm the role of the wolves as reservoir and spreaders of various helminths, some of which potentially zoonotic. These findings agree with a similar study carried out in the same area that revealed roundworms and hookworms are the most frequently detected intestinal helminths in this species (Paoletti et al. 
2017). In this study, E. granolosus, A. vasorum, and $G$. duodenalis were also detected. Generally, the infection of wolves with parasites could result as a direct transmission from other wild and domestic canids (e.g., T. vulpis, and $C$. aerophila) (Urquhart et al. 1996; Paoletti et al. 2017) or predation of infected intermediate hosts (Sarcocystis spp. and $E$. granulosus) (Bryan et al. 2012; Friesen and Roth 2016). As apex predator, wolves host a gastrointestinal parasite community that should vary in relation to the diet (Bryan et al. 2012; Friesen and Roth 2016).

Echinococcus granulosus sensu stricto (sheep strain genotype G1) is a common gastrointestinal parasite whose life cycle depends upon the predator-prey relationship (Friesen and Roth 2016) and it is an important emerging and reemerging zoonotic agent, above all in the Mediterranean basin (Poglayen et al. 2017). Ungulates often comprise the majority of wolf diet (Meriggi et al. 2011), but no wild cycle of $E$. granulosus has been described in Italy (Di Paolo et al. 2017). Therefore, the presence of echinococcosis in the MC pack is probably linked to predation on domestic animals, as suggested by the predation activity registered during the sampling sessions. Indeed, a consistent population of small ruminants, cattle, and equids grazing within the MNP area during a period ranging from June to late November is distributed in about 93 farms (Angelucci S, personal communication). The sequence analysis of E. granulosus derived from the MC pack, revealing an identity of $100 \%$ with the ovine genotype G1, endorses our hypothesis, along with the recovery of remains of predations of sheep detected during the sampling session. To date, no information relating the prevalence of echinococcosis in sheep and cattle of the Park are available. However, the lower detection rate observed in this study, compared with what was reported by others (Gori et al. 2015; Poglayen et al. 2017), suggests a low prevalence of the parasite in livestock inhabiting the same area of the wolfs' pack. In addition, the wild boar, as a contamination source for echinococcosis in wild carnivores, could not be ruled out. Indeed, the ovine genotype G1 of E. granulosus was recently described in 8 out of 765 wild boars examined during hunting season in Central Italy (Paoletti et al. 2019).

As regards A. vasorum, in Italy, the first report involved red foxes over 20 years ago (Poli et al. 1991), and since then it has been detected with increasing frequency in dogs and foxes, and now the parasite is considered endemic throughout the country (Traversa et al. 2013; Eleni et al. 2014a). Actually, only four records of $A$. vasorum from wolves have been published (Segovia et al. 2001; Eleni et al. 2014b; De Liberato et al. 2017). In particular, in Central Italy, a prevalence of $28.0 \%$ was reported, probably due to the environmental and climatic conditions (milder temperatures, higher humidity) of this area, particularly favorable to the development of the gastropods, recognized as intermediate hosts of $A$. vasorum (Taubert et al. 2009; De Liberato et al. 2017). Indeed, Eleni et al. (2014a) reported a similarly prevalence in foxes originating from the same areas, possibly indicating that natural areas of Central Italy are particularly favorable to this parasite. These data raise the question of whether wolves can be considered ancestral hosts of this parasite, like a sylvatic reservoir from which the dogs are presumably infected, or whether infection in wolves results from more recent spillover from dogs (Eleni et al. 2014b). In this study, A. vasorum was detected for the first time in the wolf population of MNP, coming from the BVO pack, which has more likelihood of interaction with dogs and human activities located in the urban area.

Finally, the canid-specific assemblage $\mathrm{C}$ of $G$. duodenalis from the MC pack suggests a possible transmission between dogs and wild canids without public health concern. Indeed, the assemblages $\mathrm{C}$ appear to be strictly host specific and are commonly found in dogs (Ryan and Cacciò 2013; Paoletti et al. 2015). To our knowledge, data relating the prevalence of Giardia spp. infection in wildlife from Central and Eastern Europe are lacking and often based only on microscopy or serological investigations without molecular characterization of the protozoa (Stojecki et al. 2015). In contrast with our findings, in Canada, Bryan et al. (2012) detected in wolf samples exclusively zoonotic assemblages of Giardia (A, B) in absence of dog-specific assemblages $(\mathrm{C}, \mathrm{D})$, probably due to the immune status, age distribution, habitats, or other ecological aspects of wolves under study. Finally, studies about Giardia spp. infections in wild wolves proved the horizontal transmission between humans, domestic animals, and wild mammals (Stronen et al. 2011) and, considering the zoonotic potential of this protozoa, further investigations in domestic and wild carnivores should be implemented in order to identify the species involved in the maintenance of the parasite in the Park territories.

In conclusion, the non-invasive method adopted in this study, based on the multidisciplinary procedures, represents an innovative tool for the survey of the Apennine wolf, able to integrate sanitary data with the ecological and demographic features of this population. The results reported in our study highlighted the presence of multiple pathogens in the wolf population of the MNP. The differences observed between $\mathrm{MC}$ and BVO packs, relative to density of animals and the characteristics of home range, seem to not affect the distribution of pathogens in each group. It cannot be ruled out that alternative wild host species (red fox, wild boar), largely distributed through the Park, could play a potential role in the transmission of the investigated pathogens.

These agents may have significant effects on the population dynamic, as described in other countries (Johnson et al. 1994; Almberg et al. 2009). However, during the monitoring activities, no alterations of the health status, the survival rate of pups, and the dynamics relative to wolf activity were 
observed, suggesting that other factors, in addition to the investigated pathogens, are necessary to determine significant mortality episodes, such as unexpected environmental changes, competition for food, pup starvation, and other causes of natural mortality (Mech et al. 2008). Then, ecological and epidemiological factors should be necessarily considered when monitoring disease in wildlife, for a correct assessment of the role, independent, synergic, or competing, played by the pathogens (Jolles et al. 2006).

\section{Compliance with ethical standards}

Conflicts of interests The authors declare that they have no conflicts of interest..

\section{References}

Alfano F, Dowgier G, Valentino MP, Galiero G, Tinelli A, Decaro N, Fusco G (2018) Identification of pantropic canine coronavirus in a wolf (Canis lupus italicus) in Italy. J Wild1 Dis 55:504-508

Almberg ES, Mech LD, Smith DW, Sheldon JW, Crabtree RL (2009) A serological survey of infectious disease in Yellowstone National Park's canid community. PLoS One 4:e7042

Balboni A, Verin R, Morandi F, Poli A, Prosperi S, Battilani M (2013) Molecular epidemiology of canine adenovirus type 1 and type 2 in free ranging red foxes (Vulpes vulpes) in Italy. Vet Microbiol 162: $551-557$

Battilani M, Scagliarini A, Tisato E, Turilli C, Jacoboni I, Casadio R, Prosperi S (2001) Analysis of canine parvovirus sequences from wolves and dogs isolated in Italy. J Gen Virol 82:1555-1560

Bergner LM, Orton RJ, da Silva FA, Shaw AE, Becker DJ, Tello C, Biek R, Streicker DG (2019) Using noninvasive metagenomics to characterize viral communities from wildlife. Mol Ecol Resour 19:128143

Blanco JC, Cortés Y (2012) Surveying wolves without snow: a critical review of the methods used in Spain. It J Mamm 23:35-48

Boitani L, Phillips M, Jhala Y (2018)Canis lupus. The IUCN red list of threatened species 2018: e.T3746A119623865 https://doi.org/10. 2305/IUCN.UK.2018-2.RLTS.T3746A119623865.en. Accessed 29 May 2019

Borecka A, Gawor J, Zieba F (2013) A survey of intestinal helminths in wild carnivores from the Tatra National Park, southern Poland. Ann Parasitol 59:169-172

Bowles J, McManus DP (1993) NADH dehydrogenase 1 gene sequences compared for species and strains of the genus Echinococcus. Int $\mathrm{J}$ Parasitol 23:969-972

Bryan HM, Darimont CT, Hill JE, Paquet PC, Thompson RC, Wagner B, Smits JE (2012) Seasonal and biogeographical patterns of gastrointestinal parasites in large carnivores: wolves in a coastal archipelago. Parasitology 139:781-790

De Liberato C, Grifoni G, Lorenzetti R, Meoli R, Cocumelli C, Mastromattei A, Scholl F, Rombolà $\mathrm{P}$, Calderini $\mathrm{P}$, Bruni $\mathrm{G}$, Eleni C (2017)Angiostrongylus vasorum in wolves in Italy: prevalence and pathological findings. Parasit Vectors 10:386

De Motes CM, Clemente-Casares P, Hundesa A, Martín M, Girones R (2004) Detection of bovine and porcine adenoviruses for tracing the source of fecal contamination. Appl Environ Microbiol 70:14481454

Di Paolo A, Piseddu T, Sebastianelli M, Manuali E, Corneli S, Paniccià M, Papa P, Viali S, Mazzone P (2017) Detection of Echinococcus granulosus G3 in a wild boar (Sus scrofa) in Central Italy using PCR and sequencing. J Wildl Dis 53:399-401

Di Sabatino D, Lorusso A, Di Francesco CE, Gentile L, Di Pirro V, Bellacicco AL, Giovannini A, Di Francesco G, Marruchella G, Marsilio F, Savini G (2014) Arctic lineage-canine distemper virus as a cause of death in Apennine wolves (Canis lupus) in Italy. PLoS One 9:e82356

Eleni C, Grifoni G, Di Egidio A, Meoli R, De Liberato C (2014a) Pathological findings of Angiostrongylus vasorum infection in red foxes (Vulpes vulpes) from Central Italy, with the first report of a disseminated infection in this host species. Parasitol Res 113:12471250

Eleni C, De Liberato C, Azam D, Morgan ER, Traversa D (2014b)Angiostrongylus vasorum in wolves in Italy. Int J Parasitol Parasites Wildl 3:12-14

Euzeby J (1981) Diagnostic expérimental des helminthoses animales: travaux pratiques d'helminthologie vétérinaire. Informations Techniques des Services Vétérinaries, Paris

Friesen OC, Roth JD (2016) Alternative prey use affects helminth parasite infections in grey wolves. J Anim Ecol 85:1265-1274

Galaverni M, Caniglia R, Fabbri E, Milanesi P, Randi E (2016) One, no one, or one hundred thousand: how many wolves are there currently in Italy? Mamm Res 61:13-24

Garcia LA, Viancelli A, Rigotto C, Pilotto MR, Esteves PA, Kunz A, Barardi CR (2012) Surveillance of human and swine adenovirus, human norovirus and swine circovirus in water samples in Santa Catarina, Brazil. J Water Health 10:445-452

Gori F, Armua-Fernandez MT, Milanesi P, Serafini M, Magi M, Deplazes P, Macchioni F (2015) The occurence of taeniids of wolves in Liguria (northern Italy). Int J Parasitol Parasites Wildl 4:252-255

Hale R, Swearer SE (2016) Ecological traps: current evidence and future directions. Proc R Soc B 283:20152647

Horak S, Leedom Larson KR (2016) Porcine adenovirus. Swine Health Information Center and Center for Food. Security and Public Health http://www.cfsph.iastate.edu/pdf/shic-factsheet-porcine-adenovirus. Accessed 29 May 2019

Hundesa A, Bofill-Mas S, Maluquer de Motes C, Rodriguez-Manzano J, Bach A, Casas M, Girones R (2010) Development of a quantitative PCR assay for the quantitation of bovine polyomavirus as a microbial source-tracking tool. J Virol Methods 163:385-389

Johnson MR, Boyd DK, Pletscher DH (1994) Serologic investigations of canine parvovirus and canine distemper in relation to wolf (Canis lupus) pup mortalities. J Wildl Dis 30:270-273

Jolles AE, Etienne RS, Olff H (2006) Independent and competing disease risks: implications for host populations in variable environments. Am Nat 167:745-757

Kumar S, Stecher G, Tamura K (2016) MEGA7: molecular evolutionary genetics analysis version 7.0 for bigger datasets. Mol Biol Evol 33: 1870-1874

LIFE08/NAT/IT/00325 (n.d.) Development of coordinated protection measures for wolf in Apennines -www.parcomajella.it/uploads/tx news/sintesi_collaboratore_2012_pubblicato.pdf. Accessed 29 May 2019

Mech LD, Goyal SM, Paul WJ, Newton WE (2008) Demographic effects of canine parvovirus on a free-ranging wolf population over 30 years. J Wildl Dis 44:824-836

Melegari I, Sarchese V, Di Profio F, Robetto S, Carella E, Bermudez Sanchez S, Orusa R, Martella V, Marsilio F, Di Martino B (2018) First molecular identification of kobuviruses in wolves (Canis lupus) in Italy. Arch Virol 163:509-513

Meriggi A, Brangi A, Schenone L, Signorelli D, Milanesi P (2011) Changes of the wolf (Canis lupus) diet in Italy in relation to the increase of wild ungulate abundance. Ethol Ecol Evol 23:195-210

Millán J, López-Bao JV, García EJ, Oleaga Á, Llaneza L, Palacios V, de la Torre A, Rodríguez A, Dubovi EJ, Esperón F (2016) Patterns of 
exposure of Iberian wolves (Canis lupus) to canine viruses in human-dominated landscapes. Ecohealth 13:123-134

Miranda C, Santos N, Parrish C, Thompson G (2017) Genetic characterization of canine parvovirus in sympatric free-ranging wild carnivores in Portugal. J Wildl Dis 53(4):824-831

Molnar B, Duchamp C, Mostl K, Diehl PA, Betschart B (2014) Comparative survey of canine parvovirus, canine distemper virus and canine enteric coronavirus infection in free-ranging wolves of Central Italy and South-Eastern France. Eur Wildl Res 60:613-624

Nelson B, Hebblewhite M, Ezenwa V, Shury T, Merrill EH, Paquet PC, Schmiegelow F, Seip D, Skinner G, Webb N (2012) Prevalence of antibodies to canine parvovirus and distemper virus in wolves in the Canadian Rocky Mountains. J Wildl Dis 48:68-76

Paoletti B, Traversa D, Iorio R, De Berardinis A, Bartolini R, Salini R, Di Cesare A (2015) Zoonotic parasites in feces and fur of stray and private dogs from Italy. Parasitol Res 114:2135-2141

Paoletti B, Iorio R, Traversa D, Di Francesco CE, Gentile L, Angelucci S, Amicucci C, Bartolini R, Marangi M, Di Cesare A (2017) Helminth infections in faecal samples of Apennine wolf (Canis lupus italicus) and Marsican brown bear (Ursus arctos marsicanus) in two protected national parks of Central Italy. Ann Parasitol 63:205-212

Paoletti B, Della Salda L, Di Cesare A, Iorio R, Vergara A, Fava C, Olivastri A, Dessì G, Scala A, Varcasia A (2019) Epidemiological survey on cystic echinococcosis in wild boar from Central Italy. Parasitol Res 118:43-46

Pizzurro F, Marcacci M, Zaccaria G, Orsini M, Cito F, Rosamilia A, Di Renzo L, Malatesta D, Di Sabatino D, Lorusso A (2017) Genome sequence of canine adenovirus type 1 isolated from a wolf (Canis lupus) in southern Italy. Genome Announc 5:e00225-e00217

Poglayen G, Gori F, Morandi B, Galuppi R, Fabbri E, Caniglia R, Milanesi P, Galaverni M, Randi E, Marchesi B, Deplazes P (2017) Italian wolves (Canis lupus italicus Altobello, 1921) and molecular detection of taeniids in the Foreste Casentinesi National Park, northern Italian Apennines. Int J Parasitol Parasites Wildl 6:1-7

Poli A, Arispici M, Mancianti F, Abramo F (1991) Pathology of naturally acquired Angiostrongylus vasorum infection in the red fox (Vulpes vulpes). Angew Parasitol 32:121-126

Ryan U, Cacciò SM (2013) Zoonotic potential of Giardia. Int J Parasitol 43:943-956

Sand HB, Zimmermann P, Wabakken P, Andren H, Pedersen HC (2005) Using GPS technology and GIS cluster analyses to estimate killrates in wolf-ungulate ecosystems. Wildl Soc Bull 33:914-925

Seamen DE, Powell RA (1996) An evaluation of the accuracy of kernel density estimators for home range analysis. Ecology 77:2075-2085
Segovia JM, Torres J, Miguel J (2001) Helminths in the wolf, Canis lupus, from North-Western Spain. J Helminthol 75:183-192

Sloss MW, Kemp RL, Zajac AM (1994) Veterinary clinical parasitology, 6th edn. Wiley- Blackwell, London, pp 3-93

Sprent JFA (1968) Notes on Ascaris and Toxascaris, with a definition of Baylisascaris gen. Nov. Parasitology 58:185-198

Stojecki K, Sroka J, Caccio SM, Cencek T, Dutkiewicz J, Kusyk P (2015) Prevalence and molecular typing of Giardia duodenalis in wildlife from eastern Poland. Folia Parasitol (Praha) 62:2015.042

Stronen AV, Sallows T, Forbes GJ, Wagner B, Paquet PC (2011) Diseases and parasites in wolves of the Riding Mountain National Park region, Manitoba, Canada. J Wildl Dis 47:222-227

Taubert A, Pantchev N, Vrhovec MG, Bauer C, Hermosilla C (2009) Lungworm infections (Angiostrongylus vasorum, Crenosoma vulpis, Aelurostrongylus abstrusus) in dogs and cats in Germany and Denmark in 2003-2007. Vet Parasitol 159:175-180

Traversa D, Giangaspero A, Molini U, Iorio R, Paoletti B, Otranto D, Giansante C (2004) Genotyping of Cryptosporidium isolates from Chamelea gallina clams in Italy. Appl Environ Microbiol 70:43674370

Traversa D, Di Cesare A, Meloni S, di Regalbono AF, Milillo P, Pampurini F, Venco L (2013) Canine angiostrongylosis in Italy: occurrence of Angiostrongylus vasorum in dogs with compatible clinical pictures. Parasitol Res 112:2473-2480

Tucciarone CM, Franzo G, Mazzetto E, Legnardi M, Caldin M, Furlanello T, Cecchinato M, Drigo M (2018) Molecular insight into Italian canine parvovirus heterogeneity and comparison with the worldwide scenario. Infect Genet Evol 66:171-179

Urquhart GM, Armour J, Duncan JL, Dunn AM, Jennings FW (1996) Veterinary parasitology. Blackwell Science, Glasgow, pp 4-57

Valerio A; Antonucci A, Giuliani A, Cobolli M, Andrisano T (2009) Wolf prey selection and food availability in the multi-prey ecosystem of Majella National Park, Abruzzo. In: L'uomo nell'ecosistema: una relazione bilanciata? XIX Congresso della Società Italiana di Ecologia "Dalle vette alpine alle profondità marine" Bolzano, 1518 settembre 2009 ISBN 978-88-88906-55-3 pp 105-120

Worton BJ (1989) Kernel methods for estimating the utility distribution in home-range studies. Ecology 70:164-168

Publisher's note Springer Nature remains neutral with regard to jurisdictional claims in published maps and institutional affiliations. 